\title{
Electromagnetism of ultramafic rocks from the Luobusa ophiolite studied at room temperatures and pressures
}

\author{
Lanfang He, Ling Chen \\ State Key Laboratory of Lithospheric \\ Evolution, \\ Institute of Geology and Geophysics, \\ Chinese Academy of Sciences \\ Beijing, China \\ mofoo@263.net
}

\author{
Xuefeng Zhao, Rujun Chen \\ Central South University
}

\author{
Weili Li, \\ BGP, CNPC
}

\begin{abstract}
It is generally accepted that a major phase of the Earth's upper mantle is represented by ultramafic rocks, including olivine pyroxenites, dunites, and peridotites. Studies on the electrical conductivity of ultramafic rocks continue to attract a great deal of interest, and much progress in the study of the electrical conductivity of rocks and minerals at high temperatures and pressures has been achieved recently. However, publications that consider the electromagnetism of ultramafic rocks at room temperatures and pressures are few and far between. In this paper, we present a study of the complex impedance properties of ultramafic samples from the Luobusa ophiolite, and their relationship to petrography. Samples were regularized and were not processed (e.g., fluid extraction, including soaking) before they were measured, and an impedance/gain-phase analyzer was used for complex impedance measurements across a frequency range, $0.005 \sim 1000 \mathrm{~Hz}$. Density, susceptibility, major minerals, and trace element contents for most of samples were measured for comprehensive analysis, but just density features and weight content of serpentine are discussed in this paper. Results show that chromite exhibits complex resistivity, far lower than harzburgite, but larger than dunite. Chromite also has more complex phases than dunite at frequencies lower than $0.02 \mathrm{~Hz}$, while at the same time exhibiting less phases at frequencies ranging from 0.02 to $1000 \mathrm{~Hz}$. In terms of resistivity, serpentine content, and sample density, resistivity increases alongside density, and serpentine content decreases. Given that serpentine content and density have a clear relationship with petrography and the degree of metamorphism of the Ophiolite complex, our study opens up new possibilities for understanding the inner structure and phases of ultramafic complexes, as well as their relationships to geological processes, using ground-based geo-electrical methods.
\end{abstract}

Keywords-Electromagnetism; Ultramafic rocks; Luobusa ophiolite ;Room conditions

\section{INTRODUCTION}

Electrical conductivity is one physical property that can be estimated using geophysical remote sensing, and is also one of the most important for study of the Earth's interior ${ }^{[1]}$. It is generally accepted that ultramafic rocks, including olivine pyroxenites, dunites, and peridotites, represent the major phase in formation of the Earth's upper mantle ${ }^{[2]}$. As a result, research on the electrical conductivity of ultramafic rocks is of great interest to geologists and geophysicists, especially in recent years. Most experimental investigations to date of the electrical properties ultramafic rocks have been conducted under high temperatures, and pressures to simulate the crust and relevant portions of the upper mantle. Understanding of the electrical conductivity of rocks and minerals, including fundamentals $s^{[1,3]}$, effects of temperature ${ }^{[2,4,5]}$, and pressure ${ }^{[6]}$, impurity and oxygen fugacity ${ }^{15,7]}$, and hydrogen (water) content $^{[7]}$, and their relationships with conductivity have been refined recently.

However, understanding of electromagnetic properties at room temperatures and pressures are important to the study of outcrop scale, and shallow-buried (i.e., less than $2 \mathrm{~km}$ ) ultramafic rocks. On the one hand, these data will provide fundamental insights to geo-electrical studies and for the exploration of these ultramafic rocks, while on the other, results from natural samples tested under room temperatures and pressures can be used as references for other studies in higher temperatures and pressures. In this paper, we present laboratory measurements of the electrical properties of ultramafic rocks sampled from the Luobusa ophiolite, southern Tibet. We also discuss the relationship between the electrical properties and petrography of these samples.

\section{GeOlogical Setting AND SAmpling}

The Luobusa ophiolite, southern Tibet, is located in the eastern portion of the Yarlung Zangbo ophiolite complex, controlled by the Indus-Yarlung Zangbo suture zone. Our study area (Fig.1) is a small, but vitally important, part of a major tectonic contact within the Yarlung Zangbo ophiolite belt, one of the best known and most extensively studied ophiolites in China ${ }^{[8,9]}$. The Luobusa ophiolite has a length of about $40 \mathrm{~km}$, a width that ranges from 0.7 to $4 \mathrm{~km}$, and an area of about $70 \mathrm{~km}^{2}$ with a general west-east trend. To the north of the Luobusa ophiolite, a suite of island-arc volcanic rock sequences are discordantly overlain by the Tertiary Luobusa group that consist of polymictic and sandy conglomerates ${ }^{[9]}$. While the southern region of the Luobusa ophiolite is in faulted contact with Upper Triassic turbidites, available outcrop and drilling results show that its major lithotypes are harzburgite and dunite (Fig.1). The contact zone between the 
harzburgite and dunite is characterized as a central ore-bearing zone; most of the chromite occurs within, or close, to this zone. The age of of the ophiolite is $130 \mathrm{Ma}$, based on the results of Wu et $\mathrm{al}^{[8]}$.. All of our samples were collected from the main body of the Luobusa ophiolite; $90 \%$ of them were sampled from the drill core, while $10 \%$ were taken from typical outcrops.

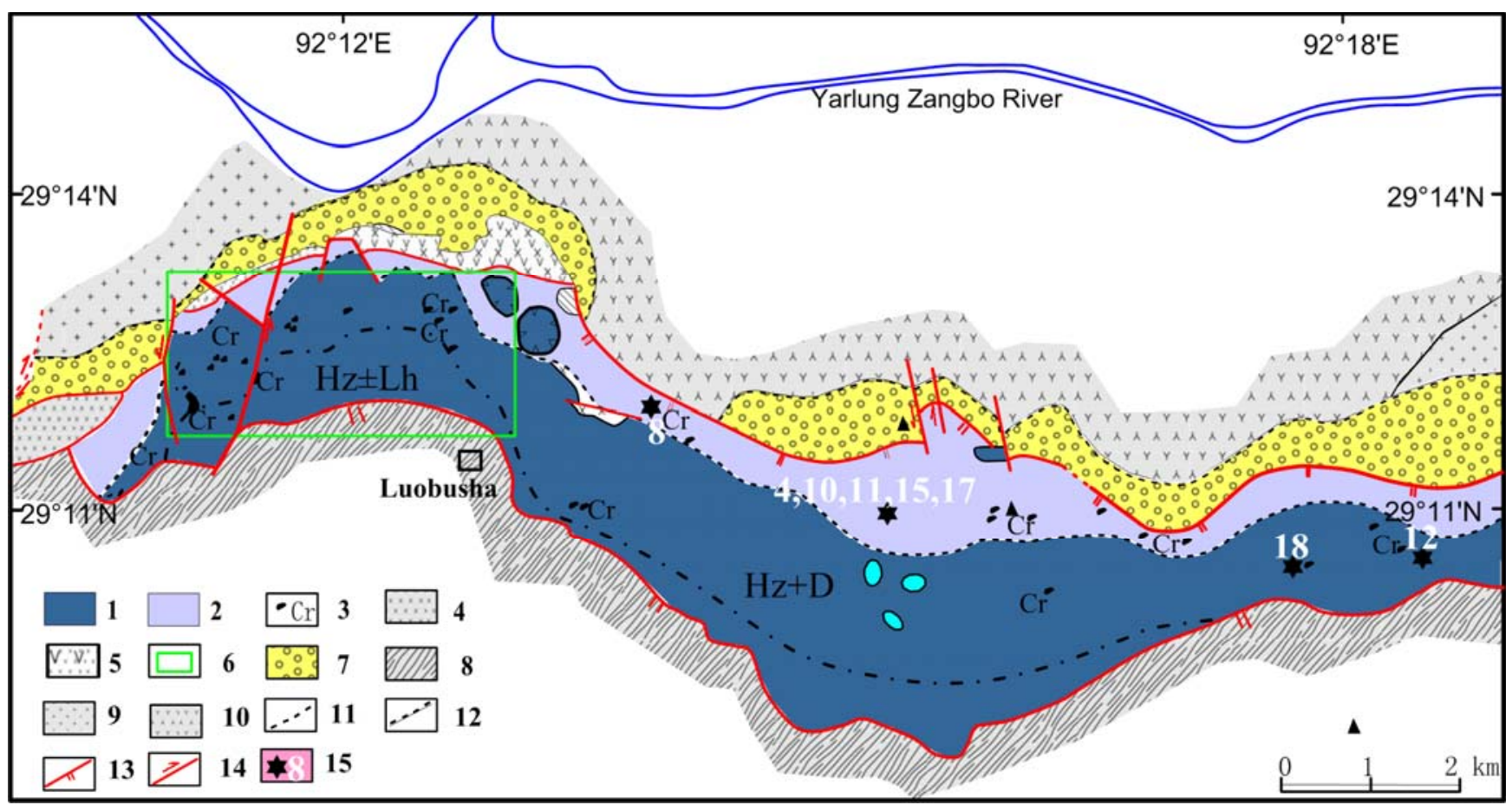

Fig.1 Schematic geological map of the Luobusa ophiolite (from He et al., 2014, modified after Li et al., 2012). Legends are as follows: 1, harzburgite (containing dunite and lherzolite); 2 , dunite; 3 , chromitite ore; 4 , cumulus bojite; 5 , cumulus of bojite and wehrlite; 6 , scope of the surface magnetic survey; 7, Luobusa group conglomerates; 8, Upper Triassic formation; 9, quartz diorite and monzonite; 10, biotite granite; 11, lithostratigraphic boundary; 12 , unconformable contact: 13 , reverse fault: 14 , strike-slip fault: 15 , sample number and position.

\section{METHODS}

\section{A. Sample Preparation}

We prepared our samples by cutting them into regular cuboids (i.e., length, $10-15 \mathrm{~cm}$; width, 5-10 cm; height, $5-10$ $\mathrm{cm})$ depending on the state of cores. All rock cores were cut to cylinders, and the remainder of each sample, after cutting, was divided into several sub-samples for thin-sectioning, major mineral and trace element testing, and scanning electron microscopy (SEM). In order to retain the original nature of rock samples for our complex resistivity measurements, no other processing, including the extraction of fluids from fissures and pores, or soaking, was carried out.

\section{B. Complex Impedance Measurements}

Complex impedance measurements (i.e., impedance spectroscopy) were taken from prepared samples under room temperatures and pressures. All samples were measured using a four-pole electrode configuration, with two outer current electrodes, and two inner potential electrodes. Two polymethyl methacrylate boxes, filled with wet flour dough mixed with copper sulfate, were used to contact the nonpolarizing electrode pairs (Fig.2). Because the current, and potential electrodes, were made of copperplate, in some cases, the reference electrode pair were used to measure the inner potential. Complex resistivity measurements were carried out using a Solartron-1260A impedance/gain-phase analyzer, while the frequency range used for impedance spectroscopy was $0.005 \sim 1000 \mathrm{~Hz}$.

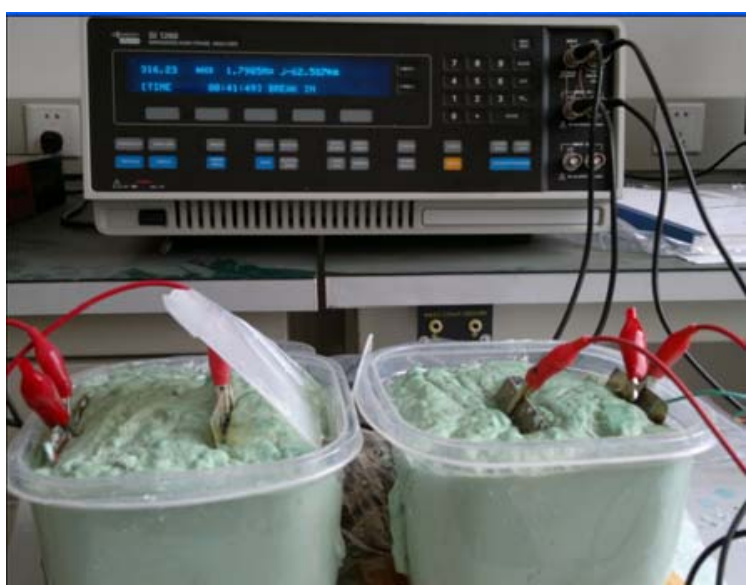

Fig.2 The complex impedance measurement system including the Solartron-1260A (on the desk), and wet flour dough mixed with copper sulfate to contact the non-polarizing electrode pair. 


\section{RESUlTS AND DisCUSSION}

In total, we measured 75 samples from the Luobusa ophiolite. Results show that the resistivity of samples varies from 10 to $10 \mathrm{M} \Omega \cdot \mathrm{m}$ around a mean of $0.85 \mathrm{M} \Omega \cdot \mathrm{m}$. Of the total sample, $20 \%$ had a resistivity less than $10 \mathrm{k} \Omega \cdot \mathrm{m}, 45 \%$ exhibited a value between 10 and $1000 \mathrm{k} \Omega \cdot \mathrm{m}$, and $35 \%$ had a

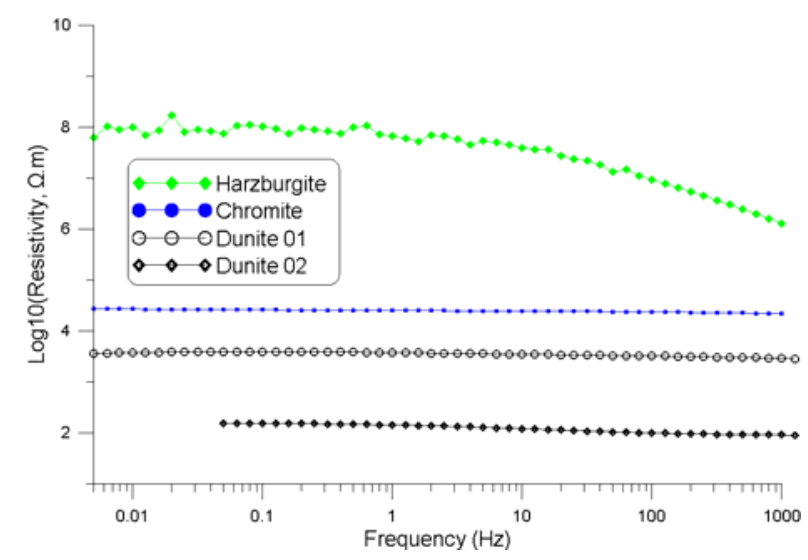

Fig.3 Complex resistivity of harzburgite, chromite, and dunite samples from the Luobusa ophiolite.

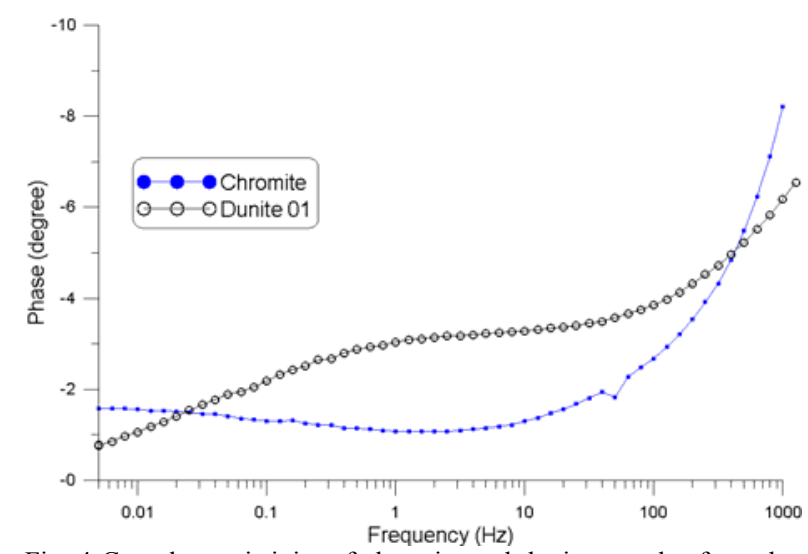

Fig. 4 Complex resistivity of chromite and dunite samples from the Luobusa ophiolite.

resistivity greater than $1000 \mathrm{k} \Omega \cdot \mathrm{m}$. Complex resistivity results measured from harzburgite, chromite, and dunite samples are shown in Fig. 3. The resistivity of harzburgite is around 100 $\mathrm{M} \Omega \cdot \mathrm{m}$ across a frequency range from 0.005 to $10 \mathrm{~Hz}$; resistivity decreases sharply with increasing frequencies greater than $10 \mathrm{~Hz}$. In contrast, while the resistivity of harzburgite is around $100 \mathrm{M} \Omega \cdot \mathrm{m}$ at frequencies ranging from 0.005 to $10 \mathrm{~Hz}$, it decreases sharply as frequency increases greater than $10 \mathrm{~Hz}$. Although the resistivity of the chromite sample is $30 \mathrm{k} \Omega \cdot \mathrm{m}$ across the whole range of frequency measurements, from 0.005 to $1000 \mathrm{~Hz}$, it decreases slowly as frequency increases. In contrast, the values for the two dunite samples are $3 \mathrm{k} \Omega \cdot \mathrm{m}$ and $150 \mathrm{k} \Omega \cdot \mathrm{m}$.

These data show that chromite exhibits a complex resistivity that is far lower than that of harzburgite, yet greater than that of dunite. Measured complex phase results for chromite and dunite samples are shown in Figure 4; note that because the impedance of harzburgite is too high to beyond the reach of $1260 \mathrm{~A}$, its complex phase is highly variable, and is thus not comparable. The phase value (in Unit of minus degree) decreases sharply as frequency changes from 1000 to $10 \mathrm{~Hz}$, then decreases slowly from 10 to $2 \mathrm{~Hz}$, and finally increases gradually at decreasing frequencies less than $2 \mathrm{~Hz}$.

Phase values for dunite decrease as the measurement frequency changes from 1000 to $0.005 \mathrm{~Hz}$. These results also show that chromite has a lower phase than dunite at a frequency range between 0.02 and $1000 \mathrm{~Hz}$, while it has a greater phase than dunite at frequencies less than $0.02 \mathrm{~Hz}$. These data indicate that very high frequencies should be used to acquire induced polarization (IP) information of chromite from a complex consisting of harzburgite, chromite, and dunite.

Most of the samples with resistivity greater than 1000 $\mathrm{k} \Omega \cdot \mathrm{m}$ are $40 \%$ or less serpentine by weight, while, in contrast, most samples that have a resistivity lower than $10 \mathrm{k} \Omega \cdot \mathrm{m}$ are more than $50 \%$ serpentine. Controlled by oxygen fugacity, fresh harzburgite, dunite, and olivine contain little serpentine; however, via metamorphism, more and more serpentinization occurs in ultramafic rocks. Thus, serpentine content is an indicator of degree of metamorphism related to geological processes, and the ultramafic rock electromagnetism can be employed for analysis of the processes related to the ophiolite complex. Regarding the relationship between resistivity and sample density (Fig.5b), results show that resistivity increases generally in line with increasing density. Half of the samples with a resistivity greater than $1000 \mathrm{k} \Omega \cdot \mathrm{m}$ also have densities greater than $3.0 \mathrm{~g} / \mathrm{cm}^{3}$, while all samples with a resistivity lower than $100 \mathrm{k} \Omega \cdot \mathrm{m}$ have densities lower than $2.8 \mathrm{~g} / \mathrm{cm}^{3}$. Because the density of rock samples from the ophiolite complex reflect both their petrography and degree of metamorphism ${ }^{[10]}$, the relationship between density and resistivity provides a new opportunity to evaluate the inner petrography and makeup of such complexes using groundbased geo-electrical methods.

\section{CONCLUSIONS}

We report the results of a study on the electromagnetism at room temperatures and pressures of ultramafic rocks from the Luobusa ophiolite. We measured and analyzed correlations between the complex impedance of samples and their petrography features, taking the density and content by weight of serpentine as an example. The resistivity of our 75 samples varies from $10 \Omega \cdot \mathrm{m}$, to $10 \mathrm{M} \Omega \cdot \mathrm{m}$, around a mean value of 0.85 
$\mathrm{M} \Omega \cdot \mathrm{m}$. The harzburgite samples had a resistivity of around $100 \mathrm{M} \Omega \cdot \mathrm{m}$, chromite of about $30 \mathrm{k} \Omega \cdot \mathrm{m}$, and dunite in the range of several hundred to several thousand $\Omega \cdot \mathrm{m}$ at frequency ranges from, or less than, 0.005 to $10 \mathrm{~Hz}$. The complex phase of chromite increases to greater than that of the dunite at low frequencies, ranging from $0.02 \mathrm{~Hz}$. Resistivity increases as density increases, and a reduction in serpentine content generally varies according to these results. Finally, our study shows that it is possible to apply ground-based geoelectrical methods to the analysis of the inner structures and phases of ultramafic complexes to understand the geological processes they have experienced.
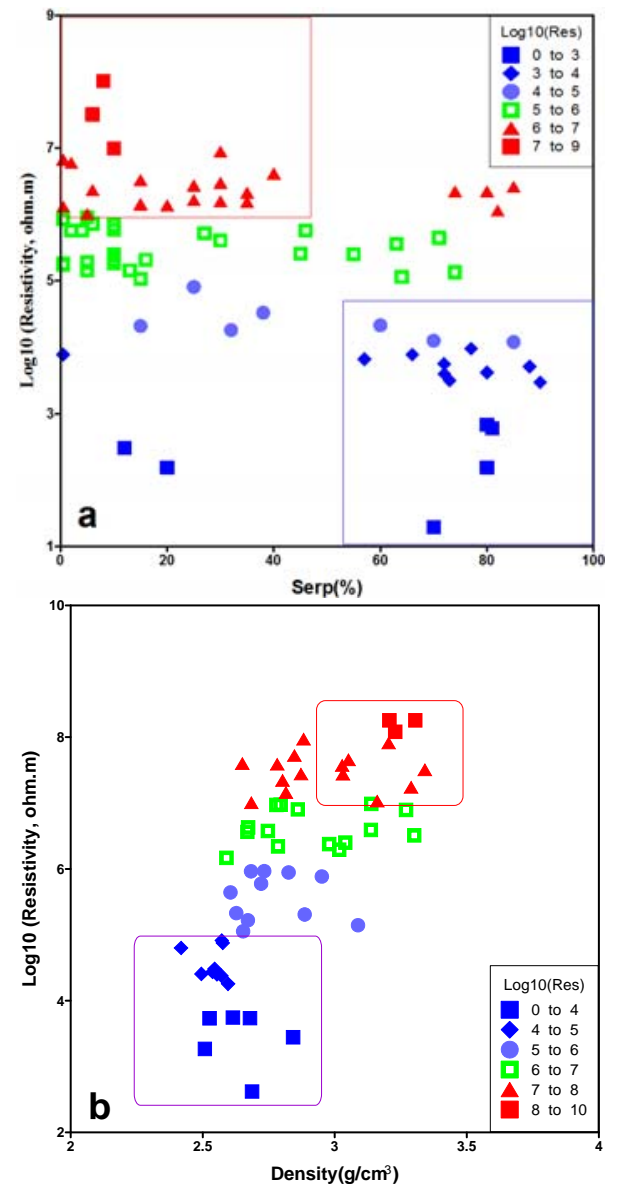

Fig.5 Relationships between resistivity, serpentine content (a), and sample density (b).

\section{ACKNOWLEDGEMENTS}

We thank Prof. Hu, Xiumian from Nanjing University for his help with petrology analyses. This research was supported by the Open Projects fund of the State Key Laboratory of Lithospheric Evolution (11611030), and by the Chinese Geological Survey geological prospecting fund (12120113095200).

\section{REFERENCES}

[1] S. I. Karato, and D. J. Wang, "Electrical conductivity of minerals and rocks", in: Karato, S. I., Physics and Chemistry of the Deep Earth: Wiley-Blackwell, 2013, pp.145-182.

[2] M. Latovikova, "Laboratory measurements of electrical properties of rocks and minerals", Geophysical Surveys, 1983, Vol 6, pp. 201-213.

[3] Yoshino,T., Ito, E., Katsura T., et al., "Effect of iron content on electrical conductivity of ferropericlase with implications for the spin transition pressure", Journal of Geophysical research, 2011, vol 116, B04202(1 9).

[4] Romano C., T. Brent., N. K, Poe., et al., "Electrical conductivities of pyrope-almandine garnets up to $19 \mathrm{GPa}$ and $1700{ }^{\circ} \mathrm{C}$ ”, American Mineralogist, 2006, vol 91, pp.1371-1377.

[5] Yoshino, T., Shimojuku, A., Shan, et al., "Effect of temperature, pressure and iron content on the electrical conductivity of olivine and its high-pressure polymorphs", Journal of Geophysical research, 2012,vol 117, B08205.

[6] Xu, Y. S., T.J. Shankland and A.G. Duba., "Pressure effect on electrical conductivity of mantle olivine", Physics of the Earth and Planetary Interiors, 2000,118, pp.149-161

[7] Wang, Q., N. Bagdassarov, Q.K., Xia, et al., "Water contents and electrical conductivity of peridotite xenoliths from the North China Craton: Implications for water distribution in the upper mantle", Lithos, 2014,vol 189, 105-126.

[8] Wu, F.Y, Liu, C.Z, Zhang, L.L., et al., "Yarlung Zangbo ophiolite: A critical updated view", Acta Petrologica Sinica, 2014, vol 30, 293-325 (In Chinese with English abstract)

[9] Bao P.S., S. Li, J. Wang, et al., "Origin of the Zedang and Luobusa Ophiolites, Tibet", ACTA Geologia Sinica (English Edition), 2014, vol 88, 669-698.

[10] He L.F., X.M. Hu, Y.B. Zha et al., "Distribution and origin of high magnetic anomalies at Luobusa Ophiolite in Southern Tibet", Chin Sci Bull, 2014,vol 59, 2898-2908. 